\title{
Long-term exercise is needed to enhance synaptic plasticity in the hippocampus
}

\author{
Anna R. Patten, ${ }^{1,2}$ Helle Sickmann, ${ }^{1,5}$ Brett N. Hryciw, ${ }^{1}{ }^{\text {Tessa Kucharsky, }}{ }^{1}$ \\ Roberta Parton, ${ }^{1}$ Aimee Kernick, ${ }^{2}$ and Brian R. Christie ${ }^{1,2,3,4,6}$ \\ ${ }^{7}$ Division of Medical Sciences, Island Medical Program, University of Victoria, Victoria, British Columbia V8P 5C2, Canada; \\ ${ }^{2}$ Department of Biology, University of Victoria, Victoria, British Columbia V8P 5C2, Canada; ${ }^{3}$ Brain Research Centre and Program \\ in Neuroscience, University of British Columbia, Vancouver, British Columbia V6T 1Z4, Canada; ${ }^{4}$ Department of Cellular and \\ Physiological Sciences, University of British Columbia, Vancouver, British Columbia V6T 1Z4, Canada
}

\begin{abstract}
Exercise can have many benefits for the body, but it also benefits the brain by increasing neurogenesis, synaptic plasticity, and performance on learning and memory tasks. The period of exercise needed to realize the structural and functional benefits for the brain have not been well delineated, and previous studies have used periods of exercise exposure that range from as little as $3 \mathrm{~d}$ to up to 6 mo. In this study, we systematically evaluated the effects of differential running periods $(3,7,14,28$, and $56 \mathrm{~d})$ on both structural (cell proliferation and maturation) and functional (in vivo LTP) changes in the dentate gyrus of adult male Sprague-Dawley rats. We found that voluntary access to a running wheel for both shortand long-term periods can increase cell proliferation in the adult DG; however, increases in neurogenesis required longer term exposure to exercise. Increases in immature neurons were not observed until animals had been running for a minimum of $14 \mathrm{~d}$. Similarly, short-term periods of wheel running did not facilitate LTP in the DG of adult animals, and reliable increases in LTP were only observed with $56 \mathrm{~d}$ of running. These results provide us with a greater understanding of the time course of wheel running access needed to enhance DG function. Furthermore, the results indicate that the new neurons produced in response to exercise in rats do not contribute significantly to synaptic plasticity until they mature.
\end{abstract}

The brain is not a static entity; rather it can show both structural and functional changes in response to environmental and experiential demands. One example of brain plasticity is adult neurogenesis. This is the process that produces new neurons in the brain and integrates them into the existing CNS circuitry throughout the life span. All areas of the brain do not exhibit neurogenesis, but it occurs robustly in the young adult hippocampus. Here, progenitor cells create neuroblasts in the subgranular zone (SGZ) of the dentate gyrus (DG) that migrate into the granule cell layer (GCL) and differentiate into excitatory dentate granule cells (Cameron et al. 1993). These new neurons incorporate themselves into existing neuronal circuits (Gheusi and Lledo 2007) and display action potentials and functional synaptic inputs similar to DG granule cells formed early in development (van Praag et al. 2002). Moreover, adult neurogenesis may be important for hippocampal-dependent learning tasks (Gould et al. 1999; Kempermann and Gage 2002) and can facilitate synaptic plasticity (van Praag et al. 1999b).

Synaptic plasticity refers to the process by which neurons alter their ability to communicate with one another. Enhancing synaptic efficacy, also known as long-term potentiation (LTP), is largely dependent upon kinase activation and protein synthesis, and serves as the primary biological mechanism for understanding how learning and memory processes operate in the brain (Bliss and Lomo 1973; Bliss and Collingridge 1993). LTP can be induced in the DG by stimulating the perforant path projections

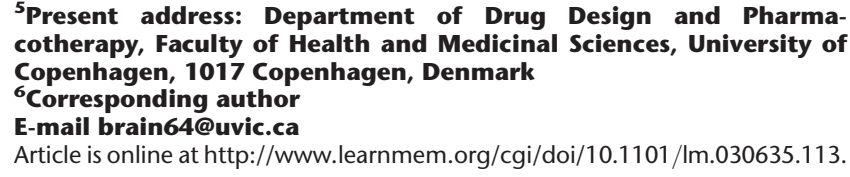

${ }^{5}$ Present address: Department of Drug Design and Pharmacotherapy, Faculty of Health and Medicinal Sciences, University of Copenhagen, 1017 Copenhagen, Denmark

${ }^{6}$ Corresponding author

E-mail brain64@uvic.ca

Article is online at http://www.learnmem.org/cgi/doi/10.1101//m.030635.113.

from the entorhinal cortex to the DG granule cells (Bliss and Lomo 1973). It has been shown that adult-generated DG granule cells receive normal excitatory input from afferents of the perforant path (van Praag et al. 2002), indicating that adult neurogenesis produces neurons that function normally and integrate into hippocampal circuitry. Interestingly, adult-born neurons have a lower threshold for the induction of LTP (Snyder et al. 2001), suggesting that this phenomenon may increase plasticity in the DG and enhance the acquisition of new memories (van Praag et al. 1999b; Kempermann 2008).

Voluntary exercise can facilitate both structural and functional plasticity and enhances cell proliferation and neurogenesis (van Praag et al. 1999a,b), synaptic plasticity (van Praag et al. 1999b; Farmer et al. 2004; Kronenberg et al. 2006; Liu et al. 2011; Titterness et al. 2011), and spatial learning (Fordyce and Wehner 1993) in both rats and mice. Because new neurons may play an important role in DG LTP and thus learning and memory (for review, see Deng et al. 2010), it is critical to understand the time course of exercise required to reliably produce benefits for both structural and functional plasticity. The aim of this study was to systematically evaluate the effects of different running periods on both structural (cell proliferation and maturation) and functional (in vivo LTP) changes in the DG of adult male Sprague-Dawley rats.

\footnotetext{
(C) 2013 Patten et al. This article is distributed exclusively by Cold Spring Harbor Laboratory Press for the first 12 months after the full-issue publication date (see http://learnmem.cshlp.org/site/misc/terms.xhtml). After 12 months, it is available under a Creative Commons License (Attribution-NonCommercial 3.0 Unported), as described at http:// creativecommons.org/licenses/by-nc/3.0/.
} 
Table 1. Weight data for control vs. exercising animals

\begin{tabular}{cccccc}
\hline & $\mathbf{3 ~ d}$ & \multicolumn{1}{c}{$\mathbf{7 d}$} & \multicolumn{1}{c}{$\mathbf{1 4} \mathbf{d}$} & \multicolumn{1}{c}{$\mathbf{2 8 ~ d}$} & \multicolumn{1}{c}{$\mathbf{5 6} \mathbf{d}$} \\
\hline Control & $353.0 \pm 2.6$ & $387.6 \pm 8.1$ & $468.3 \pm 20.8$ & $456.3 \pm 12.6$ & $591.0 \pm 26.8$ \\
Runner & $338.6 \pm 5.6$ & $378.8 \pm 6.5$ & $404.0 \pm 7.7$ & $443.6 \pm 8.3$ & $520.4 \pm 17.8^{* *}$ \\
\hline
\end{tabular}

$\left({ }^{* *}\right) P<0.01$ compared to $56-\mathrm{d}$ control animals.

\section{Results}

\section{Weight data}

A two-way ANOVA for age and group (control or runner) was used to evaluate the weights of the animals at the time of sacrifice. As expected, there was a significant main effect of age, with older animals weighing considerably more than younger animals $\left(F_{(4,75)}=\right.$ 74.51, $P<0.0001)$, see Table 1 . There was also a main effect of group $\left(F_{(1,75)}=16.3, P<0.001\right)$ and an interaction between age and group $\left(F_{(4,75)}=2.61, P<0.05\right)$. Tukey's post-hoc analysis revealed that animals given access to a running wheel for $56 \mathrm{~d}$ weighed significantly less than control animals that were sedentary for $56 \mathrm{~d}(P<0.01)$.

\section{Running distance}

The distance run per day (in kilometers per animal per day) increased considerably the longer the animal was given access to the running wheel $\left(F_{(5,25)}=5.67, P=0.001\right)$ (Fig. 1). After 28 and $56 \mathrm{~d}$, there was more than a $100 \%$ increase in running distance per day compared to animals that ran for only $3 \mathrm{~d}(28 \mathrm{~d}$, $P<0.01 ; 56 \mathrm{~d}, P<0.05)$.

\section{Effect of exercise on cell proliferation and immature neuron numbers}

To investigate whether exercise affected the actual number of neurons (and hence volume) in the GCL, we performed crosssectional area measurements to estimate the total volume of the GCL of the DG using Cavalieri's principle. No main effects of condition (runner or control) or days running were observed $\left(F_{(3,37) \text {, }}\right.$ $P=0.719)$ for total GCL volumes. Consequently, it was not necessary to convert total cell counts to cell densities for further analysis.

Exercise significantly increased cell proliferation after $3 \mathrm{~d}$ of running $(P<0.05), 7 \mathrm{~d}$ of running $(P<0.05)$, and $28 \mathrm{~d}$ of running $(P<0.01)$ (Fig. 2). Although a trend toward an increase in proliferation was observed after $14 \mathrm{~d}$ of running, this did not reach significance $(P=0.09)$.

Wheel running access for 3 or $7 \mathrm{~d}$ did not significantly increase the number of immature neurons as assessed by NeuroD staining ( $P=0.69$ and $P=0.24$, respectively) (Fig. 3). However, longer periods of access to the running wheel significantly increased the number of immature neurons in the DG, $14 \mathrm{~d}(P<$ $0.01)$ and $28 \mathrm{~d}(P<0.05)$.

\section{Effect of exercise on synaptic plasticity}

To determine whether there is a link between the amount of exercise (i.e., number of days of running) and the degree of synaptic plasticity in the DG, we examined LTP in vivo in animals from all running time periods along with their age-matched controls. LTP in the DG of sedentary control animals was $27.3 \pm 2.5 \% 1 \mathrm{~h}$ following weak theta stimulation (Fig. 4). A one-way ANOVA revealed a significant main effect of running $\left(F_{(5,70)}=2.80, P<\right.$ 0.05 ) and a one-way Dunnett post-hoc test (with the assumption that runners would have higher LTP than controls) revealed that $56 \mathrm{~d}$ of voluntary running wheel access significantly increased LTP compared to control animals $(P<0.05)$. LTP in the DG of the 56-d running group was $37.1 \pm$ $3.5 \% 1 \mathrm{~h}$ following weak theta burst stimulation (Fig. 4E).

Running for shorter periods (3-28 d) did not significantly increase LTP beyond control levels. It is possible that weak theta burst stimulation $(100 \mathrm{~Hz})$ is below the threshold for induction of changes in synaptic efficacy with these shorter time periods of running. To evaluate this hypothesis, strong theta burst stimulation $(400 \mathrm{~Hz})$ was used to induce LTP in animals that had access to voluntary running for $14 \mathrm{~d}$. Under control conditions LTP was $30.3 \pm 2.8 \% 1 \mathrm{~h}$ after strong theta burst stimulation and 14 $\mathrm{d}$ of voluntary exercise did not lead to increased synaptic efficacy in adult rats $\left(\mathrm{LTP}=34.7 \pm 1.7 \%, F_{(4,14)}=1.44, P=0.27\right)$.

\section{Discussion}

\section{Both short- and long-term exercise increase cell proliferation}

Exercise increased cell proliferation (Fig. 2), and this was observed after just $3 \mathrm{~d}$ of voluntary exercise, and at all time points following. These results are in accordance with previous literature that has shown that the effect of exercise on proliferation begins at $3 \mathrm{~d}$ (Ferreira et al. 2011) and also occurs with longer periods of running (Farmer et al. 2004; Eadie et al. 2005).

\section{Exercise increases the number of immature neurons in the dentate gyrus}

NeuroD expression was significantly increased after 14 and $28 \mathrm{~d}$ of running. These results were expected due to the time course of neuronal differentiation-the progression between proliferating cells and neuronal differentiation takes between 7 and $14 \mathrm{~d}$ (Duan et al. 2008), thus explaining why increases in the presence of immature neurons were not observed after just 3 and $7 \mathrm{~d}$ of running. These results are comparable to those of Kronenberg et al. (2006) who also saw increases in neuronal differentiation using the marker doublecortin after 10 and $32 \mathrm{~d}$ of running, but not after $3 \mathrm{~d}$ of running. As with cell proliferation, the percent increase in the number of immature neurons was similar between animals that had access to the running wheel for $14 \mathrm{~d}$ and those that had access for $28 \mathrm{~d}$ (data not shown).

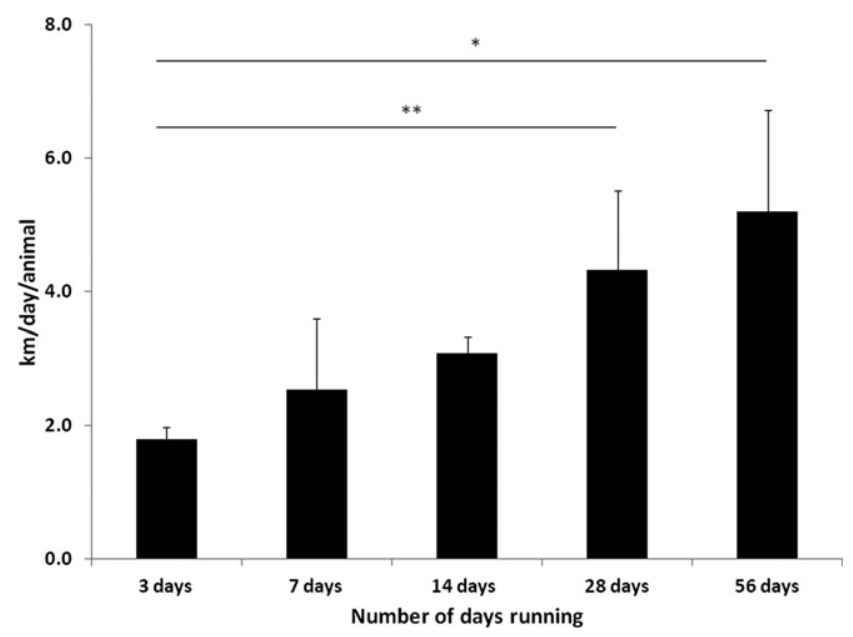

Figure 1. Distance run per animal per day. As the period of time with access to the running wheel increased, there was a parallel increase in the distance run in kilometers per day (km/d). $\left(^{*}\right) P<0.05,\left({ }^{* *}\right) P<0.01$. 

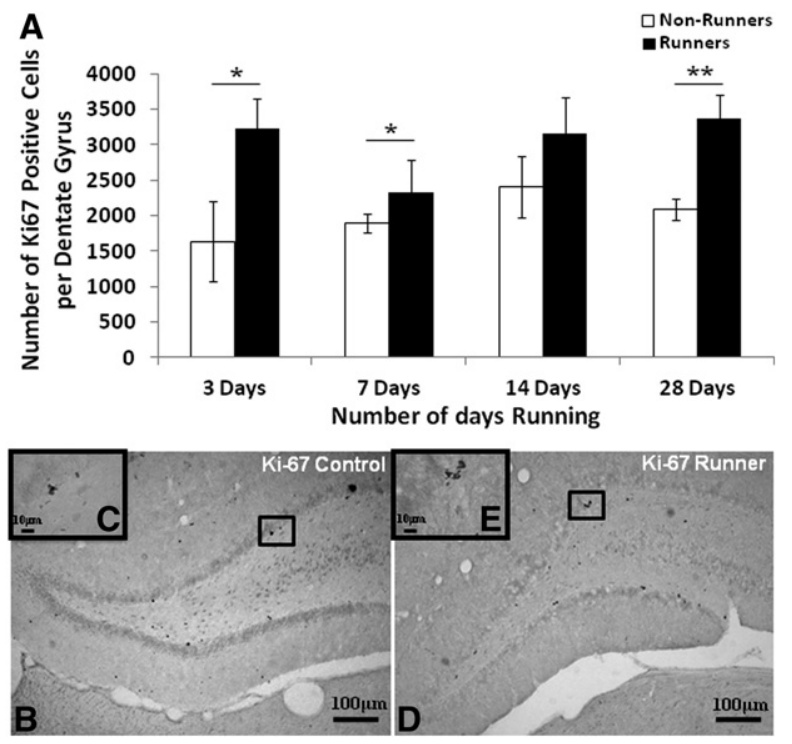

Figure 2. The effect of running on the number of proliferating cells in the granule cell layer of the DG. (A) Cell proliferation was examined using the endogenous marker Ki-67. Running for as little as $3 \mathrm{~d}$ was enough to increase cell proliferation and increases in proliferation were observed with all periods of running examined. $\left(^{*}\right) P<0.05,\left({ }^{* *}\right) P<$ 0.01 . Representative micrographs from a control $(B, C)$ and runner $(D, E)$ immunolabeled for Ki-67. Magnification, $4 \times(B, D)$ or $40 \times(C, E)$. Bars, $100 \mu \mathrm{m}(B, D)$ or $10 \mu \mathrm{m}(C, E)$.

Although the positive effect of voluntary running was still observed after $28 \mathrm{~d}$, the overall NeuroD expression observed in both the nonrunners and runners was significantly reduced compared to the amount of NeuroD expression observed at earlier time points. This effect was unexpected and the exact reason for this decrease is unclear, particularly because the same trend was not observed in proliferation levels (Ki-67). Proliferation and neuronal differentiation decrease with age (Gil-Mohapel et al. 2013), with a major decrease occurring at 3 mo of age in mice. The rats that ran for $28 \mathrm{~d}$ were $3 \mathrm{mo}$ of age at the time of sacrifice so it is possible that these overall decreases are due to the natural aging process.

\section{Exercise and synaptic plasticity}

Voluntary exercise for up to $28 \mathrm{~d}$ was unable to increase LTP induction in adult male rats. However, when access to the running wheel was increased to $56 \mathrm{~d}$ enhanced LTPs were observed. This is in contrast to other studies, including previous studies from our laboratory, that have shown increases in LTP following voluntary exercise paradigms lasting for as little as $7 \mathrm{~d}$ (Farmer et al. 2004; Christie et al. 2008; Liu et al. 2011). A further study has shown that 1 mo of running increases DG LTP, enhances acquisition of the Morris water maze task, and increases proliferation (measured by BrdU labeling) in mice (van Praag et al. 1999b). Although in our study we observed increases in proliferation similar to the BrdU results in the study of van Praag et al. (1999b), we could not replicate the increases in LTP. Farmer et al. (2004) have also shown that exercise can increase synaptic plasticity through enhanced NMDA-dependent LTP in rats, and similar increases in DG LTP have been shown in vitro in mice (van Praag et al. 1999b; Vasuta et al. 2007) and rats (Christie et al. 2005), and in the CA1 region in mice (Duffy et al. 2001), so a species difference could not be the cause of the differences in effects that we observe. However, Farmer et al. (2004) observed no LTP in control animals with $100-\mathrm{Hz}$ stimulation and only observed a $27 \%$ increase in LTP in control animals with $400-\mathrm{Hz}$ stimulation. In our study, $100 \mathrm{~Hz}$ was used to induce LTP and under these conditions we observed $27.3 \%$ LTP in controls (i.e., nonrunners), which is much higher than that reported by Farmer et al. (2004). In the present study, using one time point ( $14 \mathrm{~d}$ of exercise) $400-\mathrm{Hz}$ stimulation was employed and this stimulation paradigm led to only a small additional increase in LTP (30.3\% LTP in controls with 400-Hz stimulation, data not shown). One possibility for the lack of additional benefit using this more intense stimulation paradigm is that it may lead to a saturation effect. LTP requires cooperative interaction between afferent fibers, and at very high stimulation intensities maximum potentiation is achieved. This results in a saturated system where increased high-frequency stimulation (HFS) cannot elicit additional LTP (Johnston and Wu 1995). On the flip side, it is also important to be aware that a stimulus threshold must be reached for the induction of LTP and running is thought to enhance LTP by lowering this threshold (Farmer et al. 2004; Titterness et al. 2011). In our study, using $100 \mathrm{~Hz}$ to induce LTP, we would not expect this relatively mild intensity to have reached saturation, and thus mask the effects of running. In our study voluntary exercise could have, in fact, lowered the threshold for LTP, but at $100-\mathrm{Hz}$ stimulation, but nonrunners were able to overcome their threshold and reach similar levels of potentiation. However, Titterness et al. (2011) found that exercise enhanced LTP in adolescent male rats, but not in female adolescent rats, regardless of stimulation intensity $(100 \mathrm{~Hz}$ or $400 \mathrm{~Hz})$. This suggests that the lack of effect of running in our study is more likely due to a very high capability for LTP in control nonrunners.

As discussed above, proliferating cells take $\sim 2$ wk to differentiate into a neuronal phenotype and it is not until this time that the neurons begin to receive functional inputs from the perforant path (van Praag et al. 2002; Ge et al. 2006). Furthermore, it is between 4 and 8 wk following the birth of new neurons when enhanced synaptic plasticity is observed (Schmidt-Hieber et al. 2004; Ge et al. 2007). If we assume that the new neurons produced
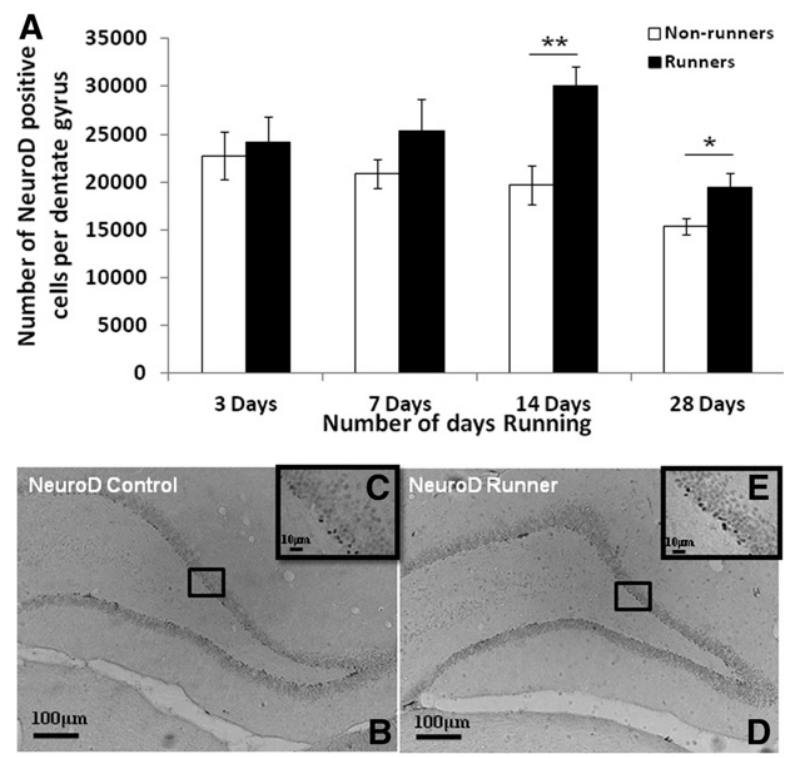

Figure 3. The effect of running on neuronal differentiation in the granule cell layer of the DG. $(A)$ Neuronal differentiation was examined using the endogenous marker NeuroD. Neuronal differentiation increased after 14 and $28 \mathrm{~d}$ of running, but increases were not observed at earlier time points. $\left({ }^{*}\right) P<0.05,\left({ }^{*}\right) P<0.01$. Representative micrographs from a control $(B, C)$ and runner $(D, E)$ immunolabeled for NeuroD. Magnification, $4 \times(B, D)$ or $40 \times(C, E)$. Bars, $100 \mu \mathrm{m}(B, D)$ or $10 \mu \mathrm{m}(C, E)$. 

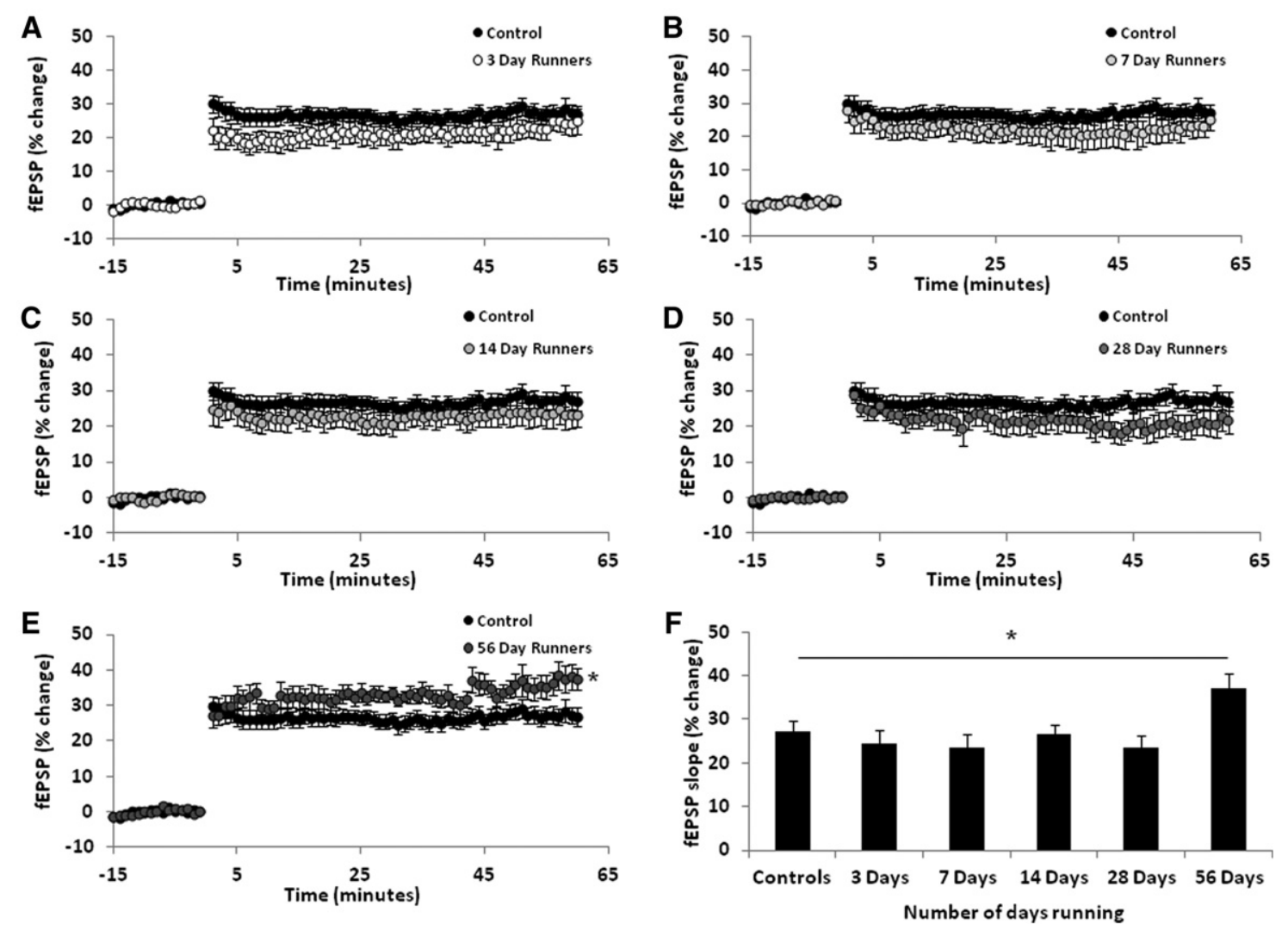

Figure 4. The effect of running on LTP in the DG measured using in vivo electrophysiology. Periods of exercise ranging from 3 to $28 \mathrm{~d}$ did not increase LTP in the DG $(A-D)$. Fifty-six days of exercise was enough to significantly increase the amount of LTP generated in the DG 60-min post-TBS $(E)$. ( $F$ ) LTP summary graph with averages of the last $5 \mathrm{~min}$ of recording (55- to 60 -min post-stimulation). LTP is significantly enhanced compared to nonrunning control animals in animals that run for $56 \mathrm{~d} .\left(^{*}\right) P<0.05$.

from exercise are contributing to the LTP measured in the DG in this study, then perhaps the reason we do not see any increases in LTP until $56 \mathrm{~d}$ of running is because the new neurons are not mature enough to contribute to LTP at the earlier time points. When animals have been running for $56 \mathrm{~d}(8 \mathrm{wk})$, the cells that began to proliferate at the beginning of the running period would be fully mature and showing enhanced synaptic plasticity at $56 \mathrm{~d}$, which may explain why increases were only observed at this time point. Another factor that should be considered is dendritic morphology. Exercise is known to enhance the length and complexity of immature neurons in the subgranular zone and may also influence the dendritic arbors of mature neurons in the DG (Eadie et al. 2005; Redila and Christie 2006; Stranahan et al. 2007). Although these changes are observed with as little as $2-3 \mathrm{wk}$ of running (Eadie et al. 2005; Redila and Christie 2006), they persist with 2 mo of running (Stranahan et al. 2007). In future studies, the time course of exercise-induced changes in dendritic morphology would be interesting to examine as these changes may correlate with changes in LTP better than changes in basal neurogenesis, as shown in the current study.

\section{Disparity between the ability of exercise to enhance neurogenesis but not LTP}

New neurons may play a role in learning and memory. Learning has been shown to selectively increase hippocampal neurogenesis in a hippocampal-dependent Morris water maze task (Gould et al. 1999; Kempermann and Gage 2002), but not all hippocampal-dependent learning and memory tasks have shown this. Furthermore, ablating neurogenesis using manipulations such as pharmacological agents, radiation, or genetic models have shown varying results as to whether neurogenesis is needed for learning and memory (Shors et al. 2001, 2002). It may be that hippocampal neurogenesis is only involved in some forms of learning and memory. This may explain why we see robust increases in proliferation and neuronal differentiation with short periods of running but no changes in LTP induction in our animals until $56 \mathrm{~d}$ of running. While the neurogenesis observed may be important for certain aspects of learning and memory, these increases may not be able to be measured through inducing NMDA-dependent LTP in the DG as we did in this study. Additional behavioral tests should be examined in these animals following different periods of exercise in order to examine the exact learning and memory processes the new neurons could be contributing to, but this is outside the realm of this study.

\section{Concluding remarks}

We have demonstrated that both short- and long-term exercise increase cell proliferation and neuronal differentiation in the adult DG. Increases in cell proliferation are significant after only $3 \mathrm{~d}$ of running, whereas increases in neuronal differentiation are not observed until at least $2 \mathrm{wk}$ of running. In our hands, exercise did not increase the capacity of LTP induced in the DG until animals had been running for $56 \mathrm{~d}$, which indicates that the new neurons produced in response to exercise are not contributing to synaptic processes in this area until well after they are mature. This disparity could indicate that enhancements in neurogenesis are improving a different aspect of learning and memory that is not measurable by the DG LTP examined in this study. 


\section{Materials and Methods}

All animal procedures were performed in accordance with the University of Victoria and Canadian Council for Animal Care policies. Male Sprague-Dawley rats were obtained from Charles River Laboratories (St. Constant, Canada) and housed in a colony room at the University of Victoria Animal Care Unit. Animals were ordered to be postnatal day (PND) 42 on the day of arrival. Animals were housed in pairs in clear polycarbonate cages $(46 \times$ $24 \times 20 \mathrm{~cm}$ ) with Carefresh contact bedding (Absorption Corp.). The room was maintained on a 12-h light-dark cycle with constant humidity and temperature $\left(22^{\circ} \mathrm{C}\right)$. Animals underwent an acclimation period in the unit of $18 \mathrm{~d}$ (until they reached PND $60)$. At PND 60, subjects were assigned to a cage that either contained a running wheel (runners) or a cage that did not (nonrunners). In either case, subjects remained in their respective cages for $3,7,14,28$, or $56 \mathrm{~d}$.

\section{Voluntary exercise}

When animals reached PND 60, they were assigned to the different experimental groups (runner or nonrunner). Animals assigned to the running group were given free access to a running wheel while their sedentary controls were left undisturbed during the same period. The running wheels were connected to a PC computer and the running distance was constantly recorded at 1-min intervals using VitalView Software (mini Mitter). The total distance ran over the period of access to the running wheel $(3,7$, 14,28 , or $56 \mathrm{~d}$ ) and was calculated and expressed as kilometers per animal per day. Half the animals in each group and at each time point were used for electrophysiological studies and half were used for immunohistochemical studies.

\section{Sacrifice and tissue processing}

Animals used for immunohistochemistry were sacrificed immediately after being removed from the running wheels (control animals were sacrificed following the running group) by transcardial perfusion. Animals were deeply anesthetized with urethane $(250 \mathrm{mg} / \mathrm{mL}$ in water; $1.5 \mathrm{~g} / \mathrm{kg}$ body weight i.p.) and then perfused with $0.9 \% \mathrm{NaCl}$ (in Tris-buffered saline [TBS]) followed by $4 \%$ paraformaldehyde (PFA) in PBS. The animal was then decapitated and the brain removed and placed in $4 \%$ PFA overnight at $4^{\circ} \mathrm{C}$. The following day, brains were transferred to a $30 \%$ sucrose solution and left until saturation occurred (determined as when the brains sunk). Brains were sliced into serial coronal sections using a freezing microtome (Model 860, American Optical Corporation) at a $30-\mu \mathrm{m}$ thickness. Samples containing the hippocampal formation (from $2.56 \mathrm{~mm}$ posterior to bregma to $6.04 \mathrm{~mm}$ anterior to bregma [Paxinos and Watson 2007]) were collected into a one-sixth section sampling fraction and stored at $4^{\circ} \mathrm{C}$ in an antifreeze cyroprotectant solution (Walters Antifreeze-0.04 M TBS, $30 \%$ ethylene glycol, 30\% glycerol) until further handling.

\section{Immunohistochemistry}

Immunohistochemistry was employed to investigate cell proliferation and neuronal differentiation. One series of brain sections was used for evaluation of cell proliferation by using an antibody for the endogenous mitotic protein $\mathrm{Ki}-67$. Ki-67 is expressed during all active phases of the cell cycle which include G1, S, G2, and M (Scholzen and Gerdes 2000). The brain sections were incubated in citric acid (dissolved in $0.1 \mathrm{M} \mathrm{TBS}$ ) for $5 \mathrm{~min}$ at $95^{\circ} \mathrm{C}$. This process was repeated twice to ensure unmasking of the antigen. After washing three times in $0.1 \mathrm{M}$ TBS, the sections were quenched in $3 \%$ hydrogen peroxide (in $0.1 \mathrm{M}$ TBS and 10\% methanol) for 10 min at room temperature. The tissue was then blocked with $5 \%$ blocking solution (0.1 M TBS with $5 \%$ normal goat serum and $0.25 \%$ Triton X-100) and incubated with a rabbit polyclonal primary antibody against Ki-67 (1:500; VP-K451, Vector Laboratories) for $48 \mathrm{~h}$ at $4^{\circ} \mathrm{C}$. Sections were rinsed in $0.1 \mathrm{M}$ TBS and further incubated with a biotin-conjugated goat anti-rabbit IgG secondary antibody (1:200; BA-1000, Vector Laboratories) in 5\% blocking solution for $2 \mathrm{~h}$ at room temperature. A further three washes were performed (0.1 M TBS) and then the sections were incubated with the avidin-biotin-peroxidase complex (Vectastain ABC Elite Kit PK4000, Vector Laboratories) for $1 \mathrm{~h}$. Three more washes were performed and then the substrate for the peroxidase reaction, 2,2-diaminobenzedine (DAB; DAB kit SK 4100, Vector Laboratories), was applied to the sections for $5 \mathrm{~min}$ at a concentration of $0.25 \mathrm{mg} / \mathrm{mL}$ in TBS with $0.01 \%$ hydrogen peroxide. $0.1 \mathrm{M}$ TBS was used to thoroughly rinse DAB from the sections.

Sections were mounted onto $2 \%$ gelatin-coated microscope slides and then dehydrated through a series of ethanol solutions of increasing concentrations $(50 \%, 70 \%, 95 \%, 100 \%)$ followed by 5 -min incubation in Citrisolv (Fisher Scientific). The slides were coverslipped immediately after incubation using a Permount medium (Fisher Scientific).

A further series of brain sections was used for evaluation of early neuronal differentiation by examining the NeuroD protein, a helix-loop-helix transcription factor that is expressed during the early stages of neuronal differentiation (Brunet and Ghysen 1999; Miyata et al. 1999). Sections were quenched in 3\% hydrogen peroxide for $15 \mathrm{~min}$ at room temperature and then washed three times in $0.1 \mathrm{M}$ TBS. Sections were blocked in 5\% blocking solution (0.1 M TBS, 5\% normal horse serum, and 0.25\% Triton X-100) and incubated with a goat polyclonal primary antibody against NeuroD (1:200; SC-1084, Santa Cruz Biotechnology) for $48 \mathrm{~h}$ at $4^{\circ} \mathrm{C}$. Sections were rinsed in $0.1 \mathrm{M}$ TBS and further incubated with a biotin-conjugated horse anti-goat IgG secondary antibody (1:200; BA-9500, Vector Laboratories) in 5\% blocking solution at room temperature for $2 \mathrm{~h}$. The bound antibodies were visualized using the methods described above.

\section{Quantification of stained cells}

All morphological analyses were performed on coded slides, with the experimenter blinded, using an Olympus BX51 microscope equipped with $10 \times, 40 \times$, and $100 \times$ objectives. Image Pro-Plus software (version 6.0 for Windows, Media Cybernetic Inc.) and a Cool Snap HQ camera (Photometrics) were used for image capture. The number of Ki-67 and NeuroD-immunopositive cells present in the SGZ of the DG of the hippocampus was quantified by manually counting all DAB-positive cells. DAB-positive cells that appeared outside of 2-3 nuclear diameters of the SGZ were not included in analysis.

\section{In vivo electrophysiology}

Animals were anesthetized with urethane $(1.5 \mathrm{mg} / \mathrm{kg})$ intraperitonally and placed on a Kopf stereotaxic apparatus. Body temperature was maintained at $37 \pm 0.5^{\circ} \mathrm{C}$ throughout the experiment with a grounded homeothermic temperature control unit (Harvard Instruments). Extracellular field potentials were recorded by inserting a $125-\mu \mathrm{m}$ stainless-steel recording electrode into the hilus of the DG (3.5 $\mathrm{mm}$ anterior, $2.0 \mathrm{~mm}$ lateral to bregma) and a $125-\mu \mathrm{m}$ monopolar stimulating electrode into the ipsilateral medial perforant path $(7.4 \mathrm{~mm}$ anterior, $4.2 \mathrm{~mm}$ lateral to bregma) (Paxinos and Watson 2007). A ground electrode was placed posterior to $\lambda$, and a reference electrode was placed anterior to bregma. Stimulating and recording electrodes were lowered to elicit a maximal response and the stimulation required to induce a 1-2 $\mathrm{mV}$ population spike was determined (dorsal-ventral [DV] coordinates between 2.8 and $3.8 \mathrm{~mm}$ ). Basal recordings were first obtained by administering a square pulse $(0.12$-msec duration) at $0.067 \mathrm{~Hz}$. Once a stable baseline was observed for at least $15 \mathrm{~min}$, LTP was induced by applying theta burst stimulation consisting of 10 bursts of five pulses at $100 \mathrm{~Hz}$ with an inter-burst interval of 200 msec which was repeated four times at 30-sec intervals. In one cohort of animals strong theta burst stimulation $(400 \mathrm{~Hz})$ was applied. The pulse duration was changed to $0.25 \mathrm{msec}$ during stimulation. Following theta burst stimulation, baseline stimulation resumed for $60 \mathrm{~min}$ as described previously (Titterness and Christie 2012).

Signals from the DG were collected using custom software (Lee Campbell; Getting Instruments). Signals were amplified (Getting Instruments), filtered $(1 \mathrm{~Hz}-3 \mathrm{kHz})$, and digitized at 5 
$\mathrm{kHz}$. For analysis the slope of the rising phase of the field EPSP was used to determine alterations in the level of synaptic efficacy. All EPSP slope data are presented as the mean percent change from the pre-conditioning baseline \pm standard error of the mean (SEM).

\section{Statistical analysis}

Statistical analysis was performed using the Statistica 7.1 analytical software (StatSoft Inc.). All data are presented as mean \pm SEM. A two-way ANOVA for time period $(3,7,14,28$, or $56 \mathrm{~d})$ and condition (control or runner) was used to examine the effect of exercise on weight gain. For neurogenesis data, independent $t$-tests were conducted for each time point comparing runners to nonrunners. DG area measurements were compared between groups using a factorial ANOVA for condition (runner vs. nonrunner) and time period of exercise.

For electrophysiological data, the control group was combined because the age difference across nonrunners (PND 63116) did not lead to significant differences in $\operatorname{LTP}\left(F_{(4,16)}=\right.$ $0.545, P=0.704)$, and a one-way ANOVA was used to examine the effect of different periods of exercise on LTP. A Dunnett posthoc test was used to compare each running group to the control group. A one-sided hypothesis was used based on previous studies (Christie et al. 2005; Titterness et al. 2011) indicating that exercise increases LTP.

\section{Acknowledgments}

We thank Jennifer Graham for technical help and expertise. A.R.P. was supported by a NeuroDevNet Doctoral Fellowship, a Neena Chappell Scholarship, and a University of Victoria Fellowship. H.S. was supported by an award from The Alfred Benzon Foundation. B.R.C. is a Michael Smith Senior Scholar and is supported by grants from the Canadian Institutes of Health Research (CIHR), the Natural Sciences and Engineering Research Council (NSERC), the Michael Smith Foundation for Health Research (MSFHR), and the Canada Foundation for Innovation (CFI).

\section{References}

Bliss TV, Collingridge GL. 1993. A synaptic model of memory: Long-term potentiation in the hippocampus. Nature 361: 31-39.

Bliss TV, Lomo T. 1973. Long-lasting potentiation of synaptic transmission in the dentate area of the anaesthetized rabbit following stimulation of the perforant path. J Physiol 232: 331-356.

Brunet JF, Ghysen A. 1999. Deconstructing cell determination: Proneural genes and neuronal identity. Bioessays 21: 313-318.

Cameron HA, Woolley CS, McEwen BS, Gould E. 1993. Differentiation of newly born neurons and glia in the dentate gyrus of the adult rat. Neuroscience 56: 337-344.

Christie BR, Swann SE, Fox CJ, Froc D, Lieblich SE, Redila V, Webber A. 2005 . Voluntary exercise rescues deficits in spatial memory and long-term potentiation in prenatal ethanol-exposed male rats. Eur J Neurosci 21: 1719-1726.

Christie BR, Eadie BD, Kannangara TS, Robillard JM, Shin J, Titterness AK. 2008. Exercising our brains: How physical activity impacts synaptic plasticity in the dentate gyrus. Neuromolecular Med 10: 47-58.

Deng W, Aimone JB, Gage FH. 2010. New neurons and new memories: How does adult hippocampal neurogenesis affect learning and memory? Nat Rev Neurosci 11: 339-350.

Duan X, Kang E, Liu CY, Ming GL, Song H. 2008. Development of neural stem cell in the adult brain. Curr Opin Neurobiol 18: 108-115.

Duffy SN, Craddock KJ, Abel T, Nguyen PV. 2001. Environmental enrichment modifies the PKA-dependence of hippocampal LTP and improves hippocampus-dependent memory. Learn Mem 8: 26-34

Eadie BD, Redila VA, Christie BR. 2005. Voluntary exercise alters the cytoarchitecture of the adult dentate gyrus by increasing cellular proliferation, dendritic complexity, and spine density. J Comp Neurol 486: $39-47$

Farmer J, Zhao X, van Praag H, Wodtke K, Gage FH, Christie BR. 2004. Effects of voluntary exercise on synaptic plasticity and gene expression in the dentate gyrus of adult male Sprague-Dawley rats in vivo. Neuroscience 124: 71-79.

Ferreira AF, Real CC, Rodrigues AC, Alves AS, Britto LR. 2011. Short-term, moderate exercise is capable of inducing structural, BDNF-independent hippocampal plasticity. Brain Res 1425: 111-122.
Fordyce DE, Wehner JM. 1993. Physical activity enhances spatial learning performance with an associated alteration in hippocampal protein kinase $\mathrm{C}$ activity in C57BL/ 6 and DBA/ 2 mice. Brain Res 619: $111-119$.

Ge S, Goh EL, Sailor KA, Kitabatake Y, Ming GL, Song H. 2006. GABA regulates synaptic integration of newly generated neurons in the adult brain. Nature 439: 589-593.

Ge S, Yang CH, Hsu KS, Ming GL, Song H. 2007. A critical period for enhanced synaptic plasticity in newly generated neurons of the adult brain. Neuron 54: 559-566.

Gheusi G, Lledo PM. 2007. Control of early events in olfactory processing by adult neurogenesis. Chem Senses 32: 397-409.

Gil-Mohapel J, Brocardo PS, Choquette W, Gothard R, Simpson J, Christie BR. 2013. Hippocampal neurogenesis levels predict watermaze search strategies in the aging brain. PLOS ONE (in press).

Gould E, Beylin A, Tanapat P, Reeves A, Shors TJ. 1999. Learning enhances adult neurogenesis in the hippocampal formation. Nat Neurosci 2: $260-265$.

Johnston D, Wu SM. 1995. Foundations of cellular neurophysiology. The MIT Press, Cambridge, MA.

Kempermann G. 2008. The neurogenic reserve hypothesis: What is adult hippocampal neurogenesis good for? Trends Neurosci 31: $163-169$

Kempermann G, Gage FH. 2002. Genetic determinants of adult hippocampal neurogenesis correlate with acquisition, but not probe trial performance, in the water maze task. Eur J Neurosci 16: $129-136$.

Kronenberg G, Bick-Sander A, Bunk E, Wolf C, Ehninger D, Kempermann G. 2006. Physical exercise prevents age-related decline in precursor cell activity in the mouse dentate gyrus. Neurobiol Aging 27: $1505-1513$.

Liu HL, Zhao G, Cai K, Zhao HH, Shi LD. 2011. Treadmill exercise prevents decline in spatial learning and memory in APP/PS1 transgenic mice through improvement of hippocampal long-term potentiation. Behav Brain Res 218: $308-314$.

Miyata T, Maeda T, Lee JE. 1999. NeuroD is required for differentiation of the granule cells in the cerebellum and hippocampus. Genes Dev 13: 1647-1652.

Paxinos G, Watson C. 2007. The rat brain in stereotaxic coordinates, 6th ed. Academic Press, San Diego.

Redila VA, Christie BR. 2006. Exercise-induced changes in dendritic structure and complexity in the adult hippocampal dentate gyrus. Neuroscience 137: 1299-1307.

Schmidt-Hieber C, Jonas P, Bischofberger J. 2004. Enhanced synaptic plasticity in newly generated granule cells of the adult hippocampus. Nature 429: 184-187.

Scholzen T, Gerdes J. 2000. The Ki-67 protein: From the known and the unknown. J Cell Physiol 182: 311-322.

Shors TJ, Miesegaes G, Beylin A, Zhao M, Rydel T, Gould E. 2001. Neurogenesis in the adult is involved in the formation of trace memories. Nature 410: 372-376.

Shors TJ, Townsend DA, Zhao M, Kozorovitskiy Y, Gould E. 2002. Neurogenesis may relate to some but not all types of hippocampal-dependent learning. Hippocampus 12: 578-584

Snyder JS, Kee N, Wojtowicz JM. 2001. Effects of adult neurogenesis on synaptic plasticity in the rat dentate gyrus. J Neurophysiol 85: 2423-2431.

Stranahan AM, Khalil D, Gould E. 2007. Running induces widespread structural alterations in the hippocampus and entorhinal cortex. Hippocampus 17: 1017-1022.

Titterness AK, Christie BR. 2012. Prenatal ethanol exposure enhances NMDAR-dependent long-term potentiation in the adolescent female dentate gyrus. Hippocampus 22: 69-81.

Titterness AK, Wiebe E, Kwasnica A, Keyes G, Christie BR. 2011. Voluntary exercise does not enhance long-term potentiation in the adolescent female dentate gyrus. Neuroscience 183: 25-31.

van Praag H, Kempermann G, Gage FH. 1999a. Running increases cell proliferation and neurogenesis in the adult mouse dentate gyrus. Nat Neurosci 2: 266-270.

van Praag H, Christie BR, Sejnowski TJ, Gage FH. 1999b. Running enhances neurogenesis, learning, and long-term potentiation in mice. Proc Natl Acad Sci 96: 13427-13431.

van Praag H, Schinder AF, Christie BR, Toni N, Palmer TD, Gage FH. 2002. Functional neurogenesis in the adult hippocampus. Nature 415: 1030-1034.

Vasuta C, Caunt C, James R, Samadi S, Schibuk E, Kannangara T, Titterness AK, Christie BR. 2007. Effects of exercise on NMDA receptor subunit contributions to bidirectional synaptic plasticity in the mouse dentate gyrus. Hippocampus 17: 1201-1208.

Received February 5, 2013; accepted in revised form July 30, 2013. 


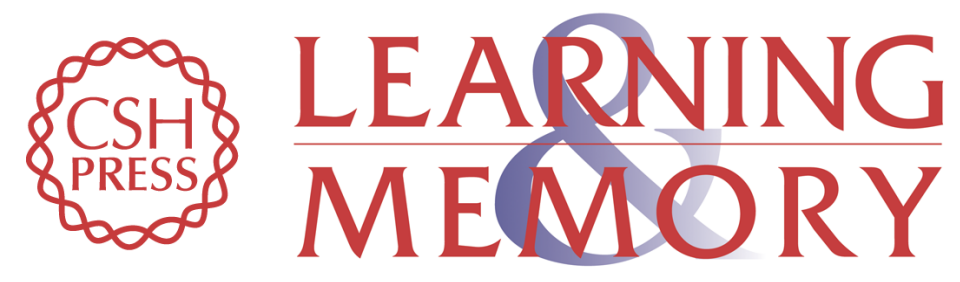

\section{Long-term exercise is needed to enhance synaptic plasticity in the hippocampus}

Anna R. Patten, Helle Sickmann, Brett N. Hryciw, et al.

Learn. Mem. 2013, 20:

Access the most recent version at doi:10.1101/Im.030635.113

References This article cites 35 articles, 3 of which can be accessed free at:

http://learnmem.cshlp.org/content/20/11/642.full.html\#ref-list-1

Creative This article is distributed exclusively by Cold Spring Harbor Laboratory Press for the

Commons

License

first 12 months after the full-issue publication date (see

http://learnmem.cshlp.org/site/misc/terms.xhtml). After 12 months, it is available under a Creative Commons License (Attribution-NonCommercial 3.0 Unported), as described at http://creativecommons.org/licenses/by-nc/3.0/.

Email Alerting Receive free email alerts when new articles cite this article - sign up in the box at the Service top right corner of the article or click here. 